Journal of Applied Fluid Mechanics, Vol. 15, No. 1, pp. 25-36, 2022.

Available online at www.jafmonline.net, ISSN 1735-3572, EISSN 1735-3645.

https://doi.org/10.47176/jafm.15.01.32828

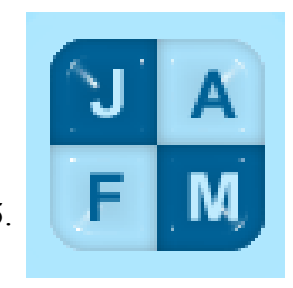

\title{
Effect of Volute Geometry on Radial Force Characteristics of Centrifugal Pump during Startup
}

\author{
R. Zhou ${ }^{1}$, J. Yang ${ }^{2}$, H. Liu ${ }^{\dagger 2}$ and L. Dong ${ }^{2}$ \\ ${ }^{1}$ Research Center of Fluid Machinery Engineering and Technology, Jiangsu University, Zhenjiang 212013 , \\ China \\ ${ }^{2}$ National Research Center of Pumps, Jiangsu University, Zhenjiang 212013, China
}

†Correspondence Author Email: liuhoulin@ujs.edu.cn

(Received March 29, 2021; accepted July 29, 2021)

\begin{abstract}
To research the effect of the volute geometry on the radial force characteristics of the centrifugal pump during the starting process, choosing a centrifugal pump with a head of $87 \mathrm{~m}$ as the research object. The pumping chamber is redesigned into a single-volute and a double-volute with similar external characteristics, and a circulation pipeline system is established. RNG $k-\varepsilon$ turbulence model is employed to calculate the unsteady starting process of two kinds of centrifugal pumps. The variation trends of radial force received by the impeller and volute during the start-up process are obtained. The radial force characteristics and internal flow field evolution of two centrifugal pumps are compared and analyzed. The results show that the radial force vector distribution of the impeller changes in spiral periodicity during the startup process, and the spiral geometry is influenced by the number of impeller blades. The direction of the spiral is opposite to the rotational speed. The double-volute geometry can effectively reduce the radial force and pulsation amplitude of the impeller during the start-up process of the centrifugal pump, reducing the radial force by about $80 \%$ at rated speed. But the radial force vector distribution of the double-volute is more complicated and disordered than the single-volute.
\end{abstract}

Keywords: Centrifugal pump; Volute geometry; Numerical simulation; Startup process; Radial force.

\section{NOMENCLATURE}

$\begin{array}{ll}b_{2} & \text { blade outlet width } \\ D_{1} & \text { impeller inlet diameter } \\ D_{2} & \text { impeller outside diameter } \\ D_{v} & \text { the minimum diameter of the shrinkage tube } \\ F & \text { radial force } \\ F_{y} & \text { radial force in the y direction } \\ F_{z} & \text { radial force in the z direction } \\ H & \text { head } \\ n & \text { rotational speed }\end{array}$

\section{INTRODUCTION}

The radial force is one of the important factors that cause the vibration and noise of the centrifugal pump during operation and shorten the service life. The radial force is relatively small under the design condition. However, the internal flow is very complex under partial working conditions, and the volute geometry is asymmetric, which makes the centrifugal pump generate a large radial force.

$\begin{array}{ll}n_{\max } & \text { rated speed } \\ n_{s} & \text { specific speed } \\ Q & \text { flow rate } \\ Q_{\text {opt }} & \text { optimal operating flow rate } \\ t & \text { start-up time } \\ t_{0} & \text { nominal acceleration time } \\ \alpha & \text { direction angle of radial force } \\ \mu & \text { efficiency }\end{array}$

Seriously, it will cause damage to the pump shaft and sealing ring. During the start-up process, the internal flow of the centrifugal pump is more complicated, the dynamic and static interference is distinct, and the pressure pulsation changes drastically. In many special applications, there are higher requirements for the pump's rapid start performance. For instance, the cooling water system of nuclear power plants, the emergency water supply system of large water transmission stations, the ship missile launching system, etc. The variations of the transient radial 
force inside the impeller and volute are very complicated, which has an important impact on these special applications that require rapid start-up. Therefore, it is particularly significant to improve the performance of the pump's rapid start-up.

Many scholars have made achievements in the research on the radial force characteristics of centrifugal pumps. Barrio et al. (2008) found that varying the blade-tongue gap within limits result in multiplying the maximum magnitude of the bladepassing frequency radial force by a factor of about 4 for low flow rates and 3 for high flow rates. Pei et al. (2014) found that changing the geometric shapes of the impeller and volute tongue could effectively reduce the pressure pulsation intensity. Shim et al. (2016) optimized the design of the double-volute centrifugal pump through the multi-objective genetic algorithm, which can better reduce the radial force and fluctuation amplitude, and improve the hydraulic efficiency. Yusoff et al. (2016) modified the geometric shape of the interface between impeller and volute of a double-volute centrifugal pump to make the amplitude of pressure pulsation more stable and improve the operation reliability of the pump. Tan et al. (2017) studied the transient dynamic characteristics of the dual-channel pump when conveying solid-liquid two-phase flow. Analyzed the influence of the pressure pulsation in the gap flow channel and the impeller diameter on the radial force and verified it through experiments. Chalghoum et al. (2018) measured the pressure fluctuation and radial force of the pump through experiments and numerical simulations, proved that the pressure fluctuations are periodic. Hao and Tan (2018) studied the radial force of pumps with different tip clearances under cavitation through experiments and simulations, found that the unsymmetrical tip clearance influences the magnitude and direction of radial force with the cavitation developing. Cui et al. (2018) studied the transient radial force of doublevolute multistage centrifugal pump under different operating conditions, and concluded that the transient radial force is closely related to the radial vibration. Shi et al. (2020) proposed a method to reduce the radial force by slotting the blades and found that the closer the slot position is to the trailing edge of the blades, the more pronounced the weakening of the radial force.

Tsukamoto et al. $(1982,1986)$ studied the transient flow characteristics of the centrifugal pump during the rapid start and stop process through experiments. Thanapandi and Prasad (1994, 1995) studied the startup and shutdown process of the centrifugal pump under different valve openings through experiments and proposed a start-stop performance prediction model. Duplaa et al. (2010) found that the water hammer phenomenon appears in the pipeline during the start-up process by experiment. Wu et al. (2010) analyzed the influence of fluid acceleration and vortex structure evolution on pump performance when the valve rapidly opened. Yang and Wang (2010) analyzed the changes in the pressure distribution on the blades and volute during the startup of the centrifugal pump and pointed out that severe pressure pulsation is an important factor leading to the unstable vibration of the impeller. $\mathrm{Hu}$ et al. (2012) studied the start-up process of three pumps with different blade numbers and analyzed the evolution of the transient flow in the impeller. $\mathrm{Li}$ et al. (2018) studied the hydraulic impact and hydraulic performance of the mixed flow pump in the process of starting acceleration and found that the starting acceleration has a significant impact on blade deformation and dynamic stress. Fu et al. (2020) found that flow separation and vortex occurs in the impeller passage during start-up, and the inner vortex core area first increases and then decreases.

The research on the influence of different volute geometries on the radial force of the centrifugal pump during the start-up process is less, so it is necessary to study the radial force of the volute geometry centrifugal pump during the starting process.

In this paper, the effect of the volute geometry on the transient flow characteristics and radial force of the centrifugal pump during start-up is investigated. Use a prototype pump with a head of $87 \mathrm{~m}$ as the object of study. Two kinds of single-volute and doublevolute centrifugal pumps with similar external characteristics are designed based on the volute geometry of the prototype pump. A circulation pipeline system is established, and a shrinkage tube is used instead of a valve. By adjusting the minimum diameter of the shrinkage tube, control the flow rate of the pump. The RNG k- $\varepsilon$ turbulence model is used. The starting process of two kinds of centrifugal pumps is calculated respectively by the unsteady numerical simulation method. The characteristics and evolution of the velocity field of centrifugal pumps during the start-up with two different volute geometry are compared and analysed. The effects of single-volute and double-volute geometries on the changes in the magnitude and vector distribution of radial forces during the start-up are compared. Verify the double-volute geometry can effectively reduce the radial force during the start-up of a centrifugal pump.

\section{SIMULATION METHODS}

\subsection{Pump geometry}

The centrifugal pump studied and analyzed in this paper has the following design parameters: flow rate $Q=217 \mathrm{~m}^{3} / \mathrm{h}$, head $H=87 \mathrm{~m}$, rated speed $n=2950 \mathrm{r} / \mathrm{min}$, specific speed $n_{\mathrm{s}}=92.8$, the number of impeller blades $Z=5$, impeller inlet diameter $D_{1}=160 \mathrm{~mm}$, impeller outside diameter $D_{2}=256 \mathrm{~mm}$, and blade outlet width $b_{2}=16 \mathrm{~mm}$. The specific speed is calculated by the following formula:

$n_{s}=\frac{3.65 n \sqrt{Q}}{H^{3 / 4}}$

Where $n$ is the rotational speed ( $\mathrm{r} / \mathrm{min}), Q$ is the flow rate $\left(\mathrm{m}^{3} / \mathrm{h}\right)$ and $H$ is the head $(\mathrm{m})$.

A pump design software is used to redesign the volute geometry, and 2D models of single-volute and double-volute are obtained. The three-dimensional 
geometry of the volute is established by using NX10.0.

To compare the radial force and internal flow of two kinds of volute centrifugal pump in the process of starting, some parameters of the volute geometry remain the same, such as the setting angle of the tongue, the length of the diffusion tube, etc. The section areas from the 5 th to the 8 th of the singlevolute are adjusted to ensure the two kinds of volute geometries conform to the same external characteristics. The 2D geometric of single-volute and double-volute is shown in Fig. 1.

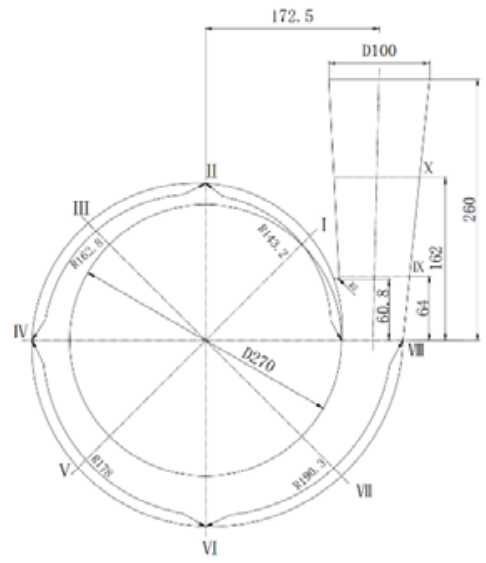

a) Single-volute geometry

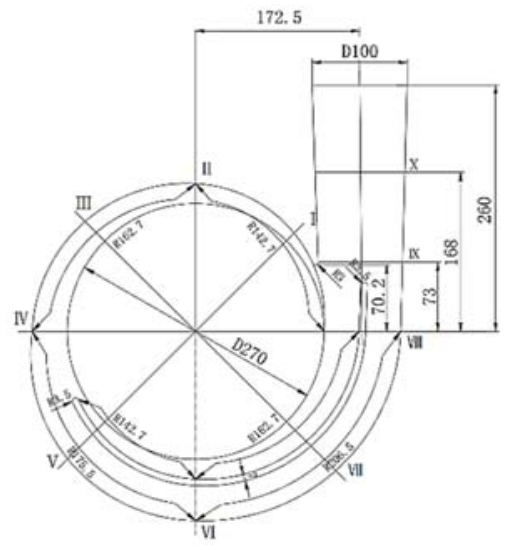

b) Double-volute geometry

Fig. 1. 2D geometry of single and double volutes.

The three-dimensional model of the circulation pipeline system is shown in Fig. 2, which is composed of a centrifugal pump, pipeline, water tank and valve. The inlet and outlet pipe diameter of the centrifugal pump are $160 \mathrm{~mm}$ and $100 \mathrm{~mm}$ respectively. The water tank is cuboid geometry with a size of $1000 \times 1000 \times 2000 \mathrm{~mm}$ and its inlet and outlet diameter are the same as the pump. The valve of the circulation pipeline system is replaced by a shrinkage tube. The performance of the centrifugal pump is close to the design conditions at rated speed by adjusting the minimum diameter of the shrinkage tube.

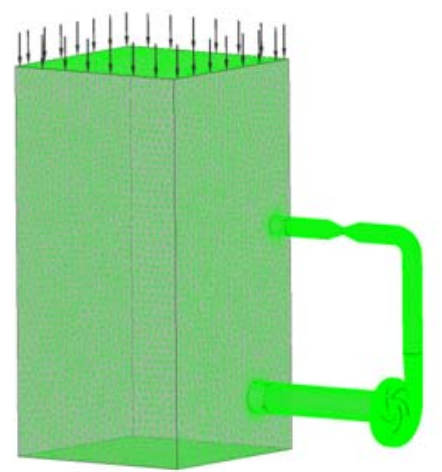

Fig. 2. Centrifugal pump system and grids.

The numerical simulation of the entire start-up process is achieved by creating a circulating pipeline system for the centrifugal pump and defining the impeller start-up speed as a function of time. This method is solved by coupling the velocity and pressure fields within the pump and circulation piping system without setting the pump inlet and outlet boundary conditions, reducing the dependence of the numerical simulation on experimentation. At the same time, the changes of the internal flow field and the parameters of the pump (flow, head, efficiency, radial force, etc.) over time can be integrally obtained during the start-up process, which is more suitable for the study of the transient start-up process of the pump. Although this method takes more time to calculate, it is more in line with the actual start-up operation.

The minimum diameter $D_{\mathrm{v}}$ of the shrinkage tube is determined through several steady-state simulation tests, as shown in Table 1. Compared with $D_{\mathrm{v}}=20 \mathrm{~mm}, D_{\mathrm{v}}=30 \mathrm{~mm}$, and $D_{\mathrm{v}}=38 \mathrm{~mm}$, when the minimum diameter $D_{\mathrm{v}}$ of the shrinkage tube is $35 \mathrm{~mm}$, the performance is closer to the design condition point of the model pump. It is calculated that the steady flow rate of the system is $213.6 \mathrm{~m}^{3} / \mathrm{h}$ at the rated speed of the pump, with a relative error is $1.6 \%$. The head is $88.7 \mathrm{~m}$, with a relative error is $1.9 \%$.

Table 1 Performance at rated speed $(n=2950 \mathrm{rpm})$

\begin{tabular}{|c|c|c|c|c|}
\hline$D_{\mathrm{v}}(\mathrm{mm})$ & 20 & 30 & 35 & 38 \\
\hline$Q\left(\mathrm{~m}^{3} / \mathrm{h}\right)$ & 96.8 & 172.3 & 213.6 & 249.1 \\
\hline$H(\mathrm{~m})$ & 108.7 & 97.5 & 88.7 & 79.8 \\
\hline
\end{tabular}

\subsection{Mesh generation}

ICEM 15.0 software is used to generate unstructured grids for single-volute and double-volute centrifugal pumps and circulation pipeline system, as shown in 
Fig. 2. To meet the requirements of numerical simulation on grid quality, the grids around the volute separator, tongue and blades are improved and smoothen. The same method is used to generate grids for single-volute and double-volute to ensure that the number and quality of grids are similar. In addition, the same model and grid are adopted for the inlet and outlet pipelines, water tank and impeller to ensure the accuracy of the study. The grid independence criterion is considered to be met when the change in the head is less than $2 \%$. Considering the efficiency of numerical calculation, the final grid number of computational domains are shown in Table 2. The total grid number of single-volute and double-volute centrifugal pumps with circulation pipeline systems are 4071404 and 4041559 respectively.

Table 2 Grid information of centrifugal pumps and system

\begin{tabular}{|c|c|c|c|c|c|}
\hline Grid number & Inlet pipeline & Outlet pipeline & Tank & Impeller & Volute \\
\hline Double-volute pump & 223304 & 612211 & 454661 & 1225092 & 1526291 \\
\hline Single-volute pump & 223304 & 612211 & 454661 & 1225092 & 1556136 \\
\hline
\end{tabular}

\subsection{Boundary conditions}

ANSYS CFX 15.0 software is used for the threedimensional unsteady calculation of the starting process of the centrifugal pump, and the Reynolds Average Navier-Stokes (RANS) method is used to describe the turbulent flow. By coupling the centrifugal pump and pipeline system to solve the change of flow rate and head during startup, there is no need to set the pump inlet and outlet boundary conditions. Set the top of the water tank as the pressure inlet, with a value of $1 \mathrm{~atm}$. The interface between the rotating region and the static region of the impeller is set to "transient rotor-stator". Meanwhile, each surface of the impeller is set as a rotating wall, and the other surfaces are set as the non-slipping wall.

The duration of the entire startup process is $1.0 \mathrm{~s}$, and the rated speed is $2950 \mathrm{r} / \mathrm{min}$. Due to the low rotating speed at the start, the time step is set as $0.001 \mathrm{~s}$, and the total time is $1.0 \mathrm{~s}$. The output frequency is set as every time step, and the residual is set as $10^{-4}$. During the start-up process, the impeller speed usually changes exponentially with time, which can be described by writing CEL expression. The equation is as follows:

$$
n=n_{\max }\left(1-e^{-t / t_{0}}\right)
$$

$n_{\max }$ is rated speed of the impeller, $2950 \mathrm{r} / \mathrm{min}$. to is the nominal acceleration time, that is, the time consumed when rotating speed changes from rest to $63.2 \%$ of the rated speed, which determine the acceleration performance. Due to the differences in the start-up acceleration performance of the motors, considering the time cost and accuracy of the calculation, $\mathrm{t}_{0}$ is set to $0.15 \mathrm{~s}$.

\subsection{Experimental verification}

To verify the accuracy of the research, the external characteristic experiment of the prototype pump and the steady-state numerical simulation of two centrifugal pumps designed in this paper under different operating conditions are carried out. During the experiment, the flow rate of the pump is controlled by adjusting the valve opening. Pressure sensors are used at the inlet and outlet to detect the pressure and calculate the head of pumps at different flow rates. At the same time, a torque meter is used to measure the motor torque and work out the pump efficiency so that the curves of head and efficiency are obtained for two centrifugal pumps under different operating conditions. Then the numerical simulation results of two centrifugal pumps are compared with the experimental data.

Figure 3 compares the hydraulic performance of single-volute and double-volute centrifugal pumps under different operating conditions. In the Fig. 3, the experimental data are the results of external characteristics of the prototype pump, and $Q_{\text {opt }}$ is the flow rate at the optimum operating conditions of the prototype pump. It can be found that the overall variation trend of the numerical simulation results is consistent with that of the experimental data. With the increase of flow, the head of the centrifugal pump tends to decrease gradually. The experimental head is higher than the numerical simulation results in the $0.6 Q_{\mathrm{opt}}$ condition, and the error of the numerical simulation results in other operating conditions is relatively small. In addition, the head of the doublevolute centrifugal pump is slightly higher than the single-volute centrifugal pump in most operating conditions. The efficiency first keeps rising with the increase of the flow rate. When under design condition, the flow rate reaches the maximum, then the efficiency decrease gradually. The efficiency obtained by numerical simulation in each condition is slightly lower than the experimental data.

On the whole, the single-volute centrifugal pump's efficiency is slightly higher than the double-volute centrifugal pump under low-flow conditions. However, under large-flow conditions, the efficiency of the single-volute centrifugal pump decreases faster as the flow rate increases, while the efficiency of the double-volute centrifugal pump remains good under large-flow conditions. So, we can show that its high-efficiency area is relatively wide. Although there are some errors between the numerical simulation results and the experimental data, the overall errors are relatively small, not more than 5\%, which is within the standard range. Under the design condition, the error of head and efficiency is 
relatively small, not more than $3 \%$. At the same time, it verified that the double-volute centrifugal pump designed in this paper has a good similarity with the prototype pump, and provides support for the

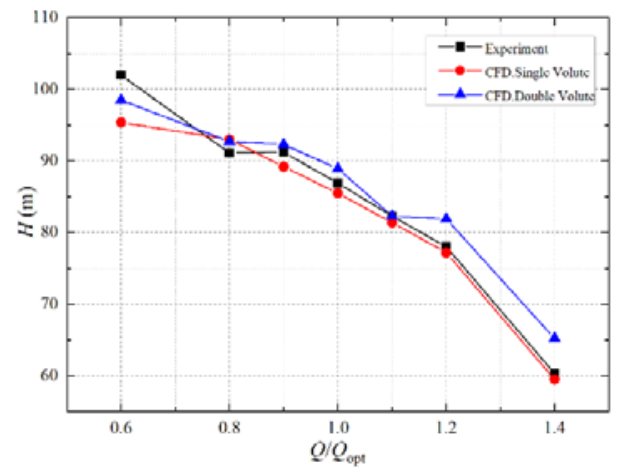

a) Flow-head curves following comparison and analysis of the influence of the two volute geometries on the performance of the pump during the start-up process.

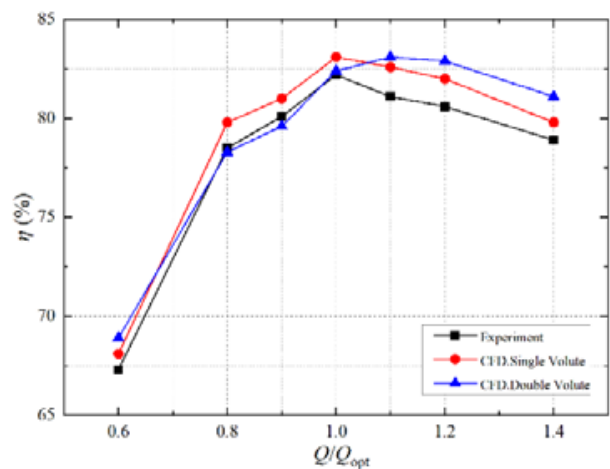

b) Flow-efficiency curves

Fig. 3. Comparison of hydraulic performance curves.

\section{RESULTS AND ANALYSIS}

\subsection{External characteristic}

Figure 4 and Fig. 5 show the curve of flow rate, head, rotating speed, and efficiency of single-volute and double-volute centrifugal pumps changing with time during startup. During the starting process, the external characteristics of the two centrifugal pumps have the same trend. The flow rate and head of the centrifugal pumps have distinct pulsation because of the influence of the rotor-stator interaction between the impeller and the volute. The flow rate of the single-volute centrifugal pump is slightly higher than the double-volute pump, but its head is a little lower. Meanwhile, the efficiency of the two pumps is similar. The external characteristics of the two kinds of centrifugal pumps are relatively consistent, which makes the characteristics of the influence of the single-volute and double-volute geometries on the radial force and internal flow field of the centrifugal pump during the start-up process more comparable.

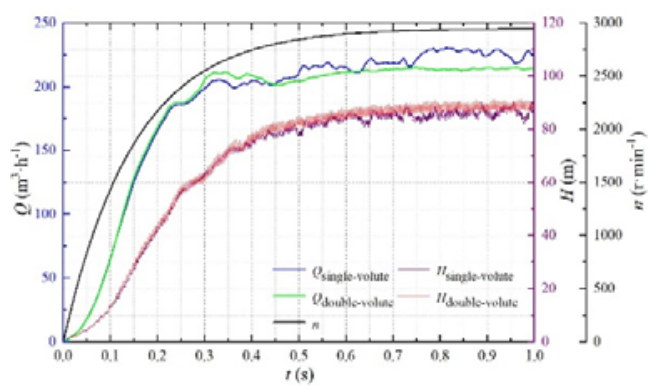

Fig. 4. Performance curves during startup.

\subsection{Internal flow field analysis}

Figure 6 and Fig. 7 are the velocity field distribution diagrams of the single-volute centrifugal pump and the double-volute centrifugal pump during the initial start-up period of $0.01 \mathrm{~s}-0.15 \mathrm{~s}$. During this period

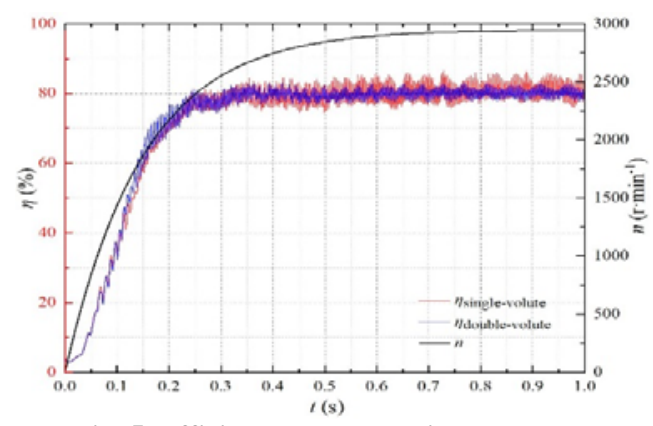

Fig. 5. Efficiency curves during startup.

time, the flow rate in the pump continues to increase, the velocity of the impeller shaft surface increases rapidly, and the relative flow angle of the blade inlet changes constantly, which makes the internal velocity field of the centrifugal pump evolve very sharply. The internal flow velocity of the impeller is mainly affected by the rotation speed, and the influence of the volute geometry is relatively small. Therefore, the changes in the internal velocity field of the impeller of the two volute geometry centrifugal pumps are similar. During $0.01 \mathrm{~s}<\mathrm{t}<0.08 \mathrm{~s}$, there is a large backflow area inside the impeller, occupying about $2 / 3$ of the flow passage. The vortex structure is very distinct, leading to distortion of the mainstream field, the disorder of the velocity field distribution, and severe flow loss inside the impeller. As the flow rate increases, the area of the backflow zone gradually shrinks, and there is a tendency to move to the middle of the blade pressure surface. At the same time, the high-speed zone at the outlet of the impeller continues to spread to the volute. At $0.1 \mathrm{~s}$, a small-scale vortex is generated on the suction surface of the blades. Because the suction surface pressure is lower and the flow velocity is relatively fast, the formed vortex is not easy to diffuse to the high-pressure side, making the vortex structure stable. After $0.15 \mathrm{~s}$, the small-scale vortex on the suction surface of the blades disappeared. The vortex and backflow areas on the pressure surface are 
attached to the blades, and the flow velocity inside the impeller is more uniform.

As shown in Fig. 6, within 0.04 s of the initial startup period, the internal flow velocity of the singlevolute is small, and the velocity gradient at the entrance of the volute is not distinct. Due to the rotorstator interference between the impeller and the volute tongue, a small area of high-speed zone appears around the volute tongue. When starting $0.04 \mathrm{~s}<\mathrm{t}<0.08 \mathrm{~s}$, the high-speed zone at the impeller channel exit gradually diffuses to the volute, resulting in a higher flow velocity around the inlet of the single-volute. And because the internal flow of the pump is small, the fluid flows into the volute under the action of inertial force, and collides with the wall of the volute, causing serious flow loss, and the velocity gradient appears to be decreasing. When $0.08 \mathrm{~s}<\mathrm{t}<0.1 \mathrm{~s}$, the area of the high-speed zone at the volute tongue increases significantly and gradually diffuses toward the outlet of the volute. The flow in

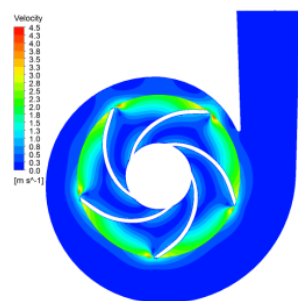

$t=0.01 \mathrm{~s}(190 \mathrm{rpm})$ $Q=2.0\left(\mathrm{~m}^{3} / \mathrm{h}\right)$

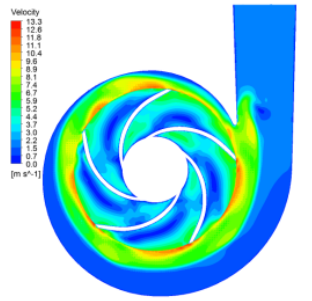

$t=0.08 \mathrm{~s}(1219 \mathrm{rpm})$ $Q=43.4\left(\mathrm{~m}^{3} / \mathrm{h}\right)$

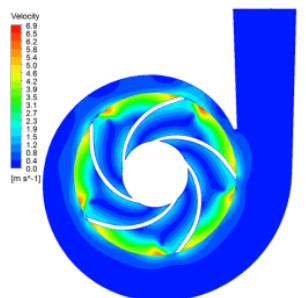

$t=0.02 \mathrm{~s}(368 \mathrm{rpm})$ $Q=4.5\left(\mathrm{~m}^{3} / \mathrm{h}\right)$

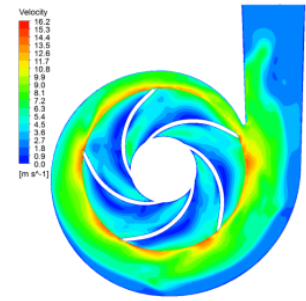

$t=0.10 \mathrm{~s}(1435 \mathrm{rpm})$ $Q=65.7\left(\mathrm{~m}^{3} / \mathrm{h}\right)$

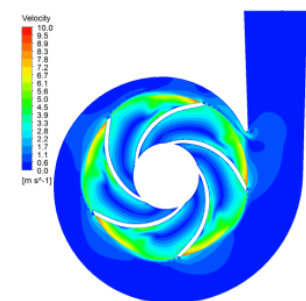

$t=0.04 \mathrm{~s}(690 \mathrm{rpm})$ $Q=11.9\left(\mathrm{~m}^{3} / \mathrm{h}\right)$

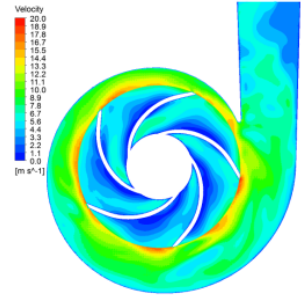

$t=0.12 \mathrm{~s}(1624 \mathrm{rpm})$ $Q=89.7\left(\mathrm{~m}^{3} / \mathrm{h}\right)$

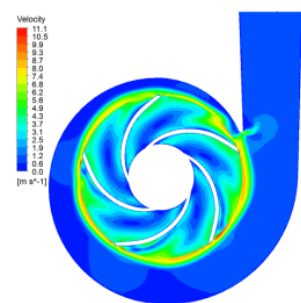

$t=0.06 \mathrm{~s}(972 \mathrm{rpm})$ $Q=25.0\left(\mathrm{~m}^{3} / \mathrm{h}\right)$

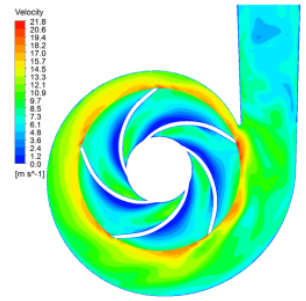

$t=0.15 \mathrm{~s}(1865 \mathrm{rpm})$ $Q=125.6\left(\mathrm{~m}^{3} / \mathrm{h}\right)$

Fig. 6. Velocity field distribution of single-volute pump within $0.01 \mathrm{~s}-0.15 \mathrm{~s}$.

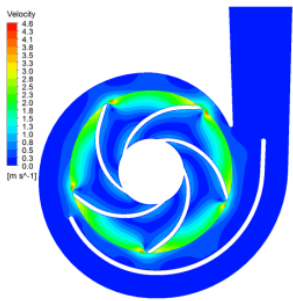

$t=0.01 \mathrm{~s}(190 \mathrm{rpm})$ $Q=2.0\left(\mathrm{~m}^{3} / \mathrm{h}\right)$

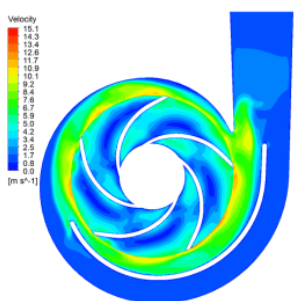

$t=0.08 \mathrm{~s}(1219 \mathrm{rpm})$ $Q=42.9\left(\mathrm{~m}^{3} / \mathrm{h}\right)$

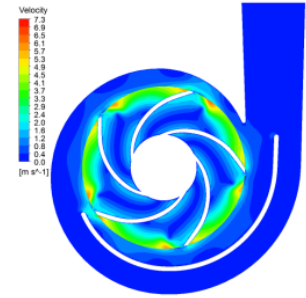

$t=0.02 \mathrm{~s}(368 \mathrm{rpm})$ $Q=4.4 \mathrm{~m}^{3} / \mathrm{h}$ )

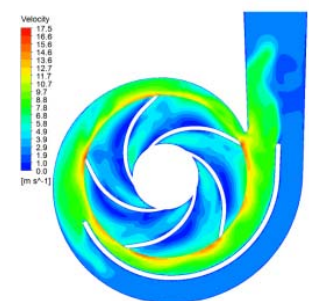

$t=0.10 \mathrm{~s}(1435 \mathrm{rpm})$ $Q=64.9\left(\mathrm{~m}^{3} / \mathrm{h}\right)$

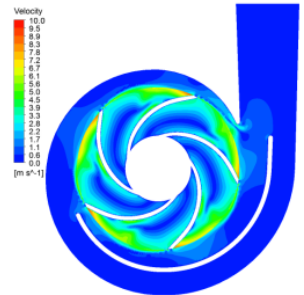

$t=0.04 \mathrm{~s}(690 \mathrm{rpm})$ $Q=11.9\left(\mathrm{~m}^{3} / \mathrm{h}\right)$

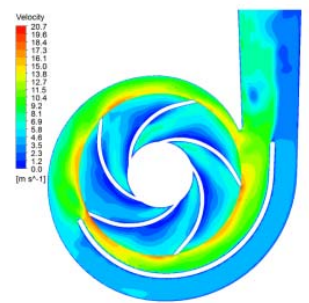

$t=0.12 \mathrm{~s}(1624 \mathrm{rpm})$ $Q=90.6\left(\mathrm{~m}^{3} / \mathrm{h}\right)$

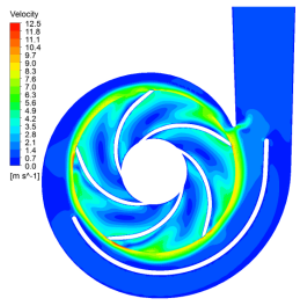

$t=0.06 \mathrm{~s}(972 \mathrm{rpm})$ $Q=24.7\left(\mathrm{~m}^{3} / \mathrm{h}\right)$

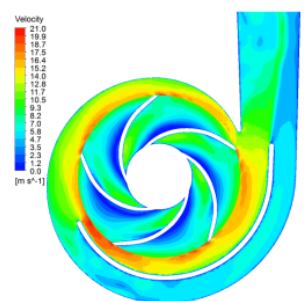

$t=0.15 s(1865 \mathrm{rpm})$ $Q=128.9\left(\mathrm{~m}^{3} / \mathrm{h}\right)$

Fig. 7. Velocity field distribution of double-volute pump within 0.01s-0.15s. 
the diffusion section of the single-volute is more turbulent, and a large-scale backflow area appears. During the period of $0.1 \mathrm{~s}<\mathrm{t}<0.15 \mathrm{~s}$, the internal flow velocity of the single-volute becomes relatively uniform, but there are many vortices of different sizes in the volute and diffusion section, the area of the high-speed zone at the volute tongue gradually decreases, and the internal flow loss is still relatively high.

Comparing the velocity field distributions of single and double volute geometries within $0.01 \mathrm{~s}<\mathrm{t}<0.15 \mathrm{~s}$ at start-up, it is found that the velocity field distribution around the double-volute splitter is different. Within $0.08 \mathrm{~s}$ of the start-up period, the internal flow velocity of the centrifugal pump is small, and the velocity field distributions in the two volutes are relatively similar. When $0.08 \mathrm{~s}<\mathrm{t}<0.15 \mathrm{~s}$, the fluid flows into the splitter inlet and collides with the initial position of the splitter violently. The kinetic energy is converted into pressure energy, resulting in the flow velocity outside the splitter is smaller. The obstruction effect on the inner side of the splitter is relatively weak, which makes the flow velocity faster. At the same time, the fluid flows out from both sides of the splitter, which produces an obvious velocity gradient in the diffusion section, and forms a larger area of backflow area near the outlet of the volute. The flow in the diffusion section of the single-volute is more turbulent than that of the double-volute. It can be seen that in the initial stage of the startup, the double-volute geometry has a certain effect on improving the internal flow state.

Figure 8 and Fig. 9 are the velocity field distribution diagrams of the centrifugal pumps with two volute geometries during the start-up process of $0.1 \mathrm{~s}-1.0 \mathrm{~s}$. Compared with the change in the $0.1 \mathrm{~s}$ period of starting, the impeller rotation acceleration is getting smaller and smaller. After $0.4 \mathrm{~s}$, the impeller gradually approaches the rated speed, the flow change is small, the internal flow state has stabilized as a whole, and there is no apparent change in the velocity field distribution at each moment. Because the pressure on the pressure surface of the blades is relatively high, the surface velocity is small, and the suction surface is just the opposite, which makes the velocity field distribution in the impeller channel more uniform. Although there is still some flow loss, the impact on the pump performance is relatively weak, which is within an acceptable range.

Figure 8 shows that the high-speed zone at the position of the tongue completely disappeared at $0.2 \mathrm{~s}$. After $0.3 \mathrm{~s}$, the vortex and backflow areas in the diffusion section disappear, and the velocity field is distributed uniformly and has good symmetry. In Fig. 9, 0.2s after start-up of the double-volute centrifugal pump, the velocity field distribution on both sides of the splitter gradually stabilizes, and the area of the high-speed zone at the volute tongue begins to shrink. The fluid in the flow channel inside the splitter is weakly affected by the blocking effect of the splitter, the loss of kinetic energy is few, and the flow speed is faster. The area of the high-speed zone at the volute tongue is larger than that of singlevolute. The flow state in the outer flow channel of the splitter is the opposite of the inner flow. The flow rate at the inlet of the outer flow channel is significantly lower, but the velocity gradient is relatively uniform. At the same time, affected by the drainage effect of the splitter, the internal flow state of the diffusion section of the double-volute is relatively stable, and the flow field distribution also has a certain symmetry.

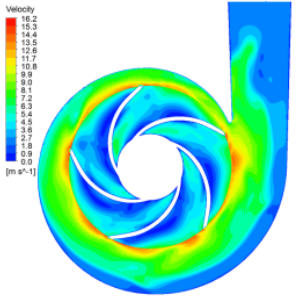

$t=0.1 \mathrm{~s}(1435 \mathrm{rpm})$ $Q=65.7\left(\mathrm{~m}^{3} / \mathrm{h}\right)$

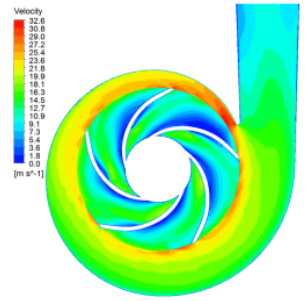

$t=0.5 \mathrm{~s}(2845 \mathrm{rpm})$ $Q=211.3\left(\mathrm{~m}^{3} / \mathrm{h}\right)$

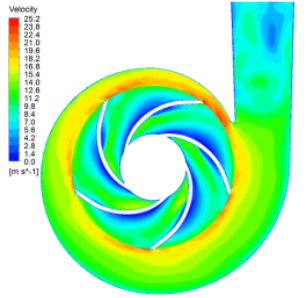

$t=0.2 \mathrm{~s}(2172 \mathrm{rpm})$ $Q=165.5\left(\mathrm{~m}^{3} / \mathrm{h}\right)$

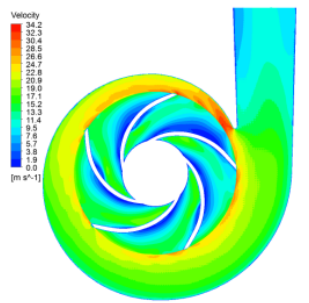

$t=0.6 \mathrm{~s}(2896 \mathrm{rpm})$

$Q=215.3\left(\mathrm{~m}^{3} / \mathrm{h}\right)$

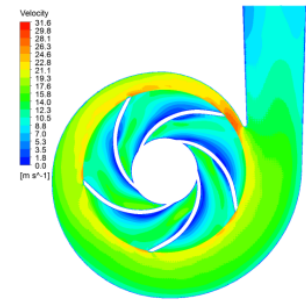

$t=0.3 s(2313 \mathrm{rpm})$ $Q=198.7\left(\mathrm{~m}^{3} / \mathbf{h}\right)$

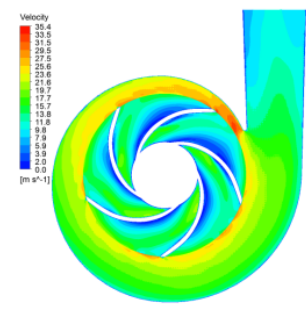

$t=0.8 \mathrm{~s}(2935 \mathrm{rpm})$ $Q=220.1\left(\mathrm{~m}^{3} / \mathbf{h}\right)$

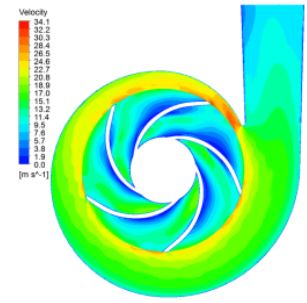

$t=0.4 \mathrm{~s}(2745 \mathrm{rpm})$ $Q=204.8\left(\mathrm{~m}^{3} / \mathrm{h}\right)$

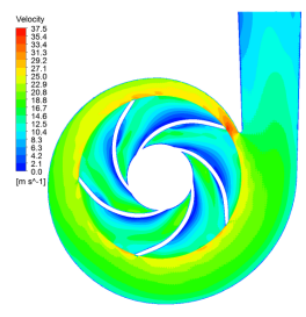

$t=1.0 \mathrm{~s}(2950 \mathrm{rpm})$

$Q=226.7\left(\mathrm{~m}^{3} / \mathrm{h}\right)$

Fig. 8. Velocity field distribution of single-volute pump within $0.1 \mathrm{~s}-1.0 \mathrm{~s}$. 


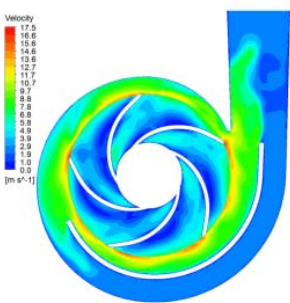

$t=0.1 \mathrm{~s}(1435 \mathrm{rpm})$ $Q=64.9\left(\mathrm{~m}^{3} / \mathrm{h}\right)$

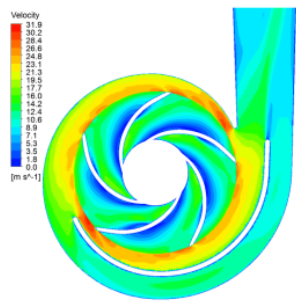

$t=0.5 \mathrm{~s}(2845 \mathrm{rpm})$ $Q=208.9\left(\mathrm{~m}^{3} / \mathrm{h}\right)$

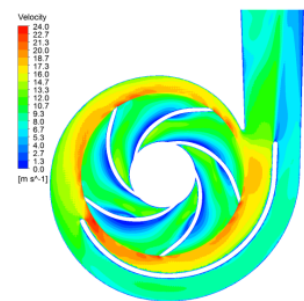

$t=0.2 s(2172 \mathrm{rpm})$ $Q=168.2\left(\mathrm{~m}^{3} / \mathrm{h}\right)$

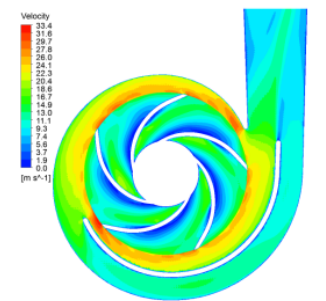

$t=0.6 s(2896 \mathrm{rpm})$

$Q=211.8\left(\mathrm{~m}^{3} / \mathrm{h}\right)$

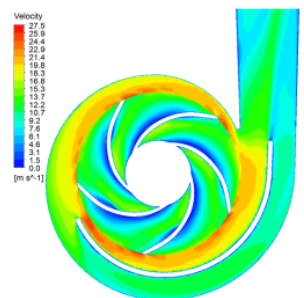

$t=0.3 s(2313 \mathrm{rpm})$ $Q=205.3\left(\mathrm{~m}^{3} / \mathrm{h}\right)$

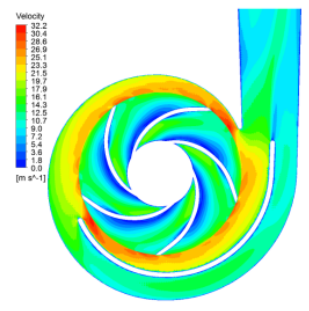

$t=0.8 \mathrm{~s}(2935 \mathrm{rpm})$ $Q=216.1\left(\mathrm{~m}^{3} / \mathrm{h}\right)$

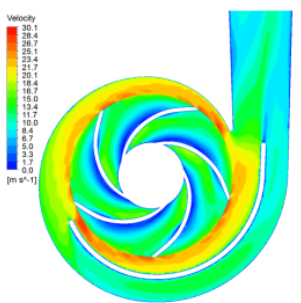

$t=0.4 \mathrm{~s}(2745 \mathrm{rpm})$ $Q=204.5\left(\mathrm{~m}^{3} / \mathrm{h}\right)$

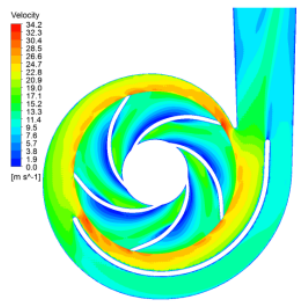

$t=1.0 s(2950 \mathrm{rpm})$ $Q=220.3\left(\mathrm{~m}^{3} / \mathrm{h}\right)$

Fig. 9. Velocity field distribution of double-volute pump within 0.1s-1.0s.

\subsection{Transient radial force scalar}

Since the impeller rotates around the $\mathrm{x}$-axis, according to the unsteady simulation results, the forces acting on each grid node on the surfaces of blades, shrouds, and the interfaces between impeller and volute are calculated in the $y$-direction and $z$ direction. Through the parallelogram theorem of force, the transient radial force of the impeller during the start-up process can be obtained. The expressions are as follows.

$$
\left\{\begin{array}{l}
F_{y}=\sum_{i=1}^{N} F_{i} \sin \alpha \\
F_{z}=\sum_{i=1}^{N} F_{i} \cos \alpha \\
F=\sqrt{F_{y}^{2}+F_{z}^{2}} \\
\alpha=\arctan \left(\frac{F_{y}}{F_{z}}\right)
\end{array}\right.
$$

In the equation, Fy and $\mathrm{Fz}$ are the component forces in the radial direction are obtained by monitoring, $\mathrm{F}$ is the radial force vector and $\alpha$ is the radial force direction angle.

Figure 10 shows the time-varying curve of the transient radial force of impellers of single-volute and double-volute centrifugal pumps during the start-up process. Affected by the rotor-stator interaction between the impeller and the volute, there are severe pressure pulsations on the surface of the impeller, which makes the transient radial force of the impeller also have distinct pulsation. Moreover, with the increase of rotating speed, the rotor-stator interaction becomes more and more intense, and the pulsation amplitude of the transient radial force of the impeller also becomes distinct.
Although there is a brief decline during the start-up period of $0.1-0.15 \mathrm{~s}$, the transient radial force of the single-volute centrifugal pump impeller maintains a rapid upward trend within $0.5 \mathrm{~s}$ of the start-up. After $0.5 \mathrm{~s}$, as the pump flow gradually approaches the design condition, the pressure distribution in the impeller passage becomes more stable. The transient radial force fluctuates at about $600 \mathrm{~N}$, and the peak value is close to $800 \mathrm{~N}$. However, within $0.15 \mathrm{~s}$ at the beginning of the startup, the transient radial force of the impeller on the double-volute centrifugal pump increased significantly and then maintained a downward trend. After starting $0.25 \mathrm{~s}$, it tends to be relatively stable and fluctuates around $120 \mathrm{~N}$ and peaking at $240 \mathrm{~N}$ at most, reducing about $80 \%$ in the mean value.

By comparing the change curves of impellers' transient radial forces of single-volute and the double-volute centrifugal pumps during the start-up process, it is clear that the radial force of impellers of two pumps is relatively equivalent within $0.1 \mathrm{~s}$. During $0.1 \mathrm{~s}$ to $0.2 \mathrm{~s}$, the impeller transient radial force of the double-volute centrifugal pump is slightly higher than the single-volute. After starting $0.2 \mathrm{~s}$, the radial force of the impeller of the singlevolute centrifugal pump is higher than the doublevolute, and the difference of radial forces of two impellers increases with the change of starting time. So the double-volute geometry can effectively reduce the radial force and pulsation amplitude of the impeller during the starting process of the centrifugal pump, which is helpful to reduce the vibration and noise generated during the starting process of the pump, improve the service life of the impeller.

Figure 11 shows the transient radial forces variation curves of two kinds of volute geometries during the start-up process. Due to the strong influence of rotating speed and flow rate during the starting 


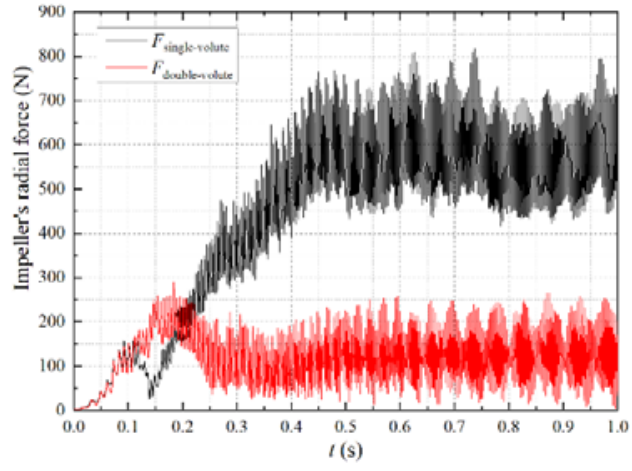

Fig. 10. Radial force curves of the impeller during startup.

process, the transient radial force of the volute increases exponentially and has apparent pulsation characteristics.

Due to the growth of flow rate and head, there is a certain hysteresis relative to rotating speed. The transient radial forces of two kinds of volutes grow slowly within $0.1 \mathrm{~s}$. During the start-up period of $0.1 \mathrm{~s}-0.4 \mathrm{~s}$, the transient radial forces of the volutes rise rapidly. After $0.4 \mathrm{~s}$, the growth gradually moderates and tends to be stable. Compared with the single-volute geometry, the radial force on the double-volute is relatively smaller, reducing about $3 \%$. Its pulsation amplitude is relatively larger, but the change is more stable. The radial force on the single-volute keeps increasing and frequent fluctuations during the start-up process.

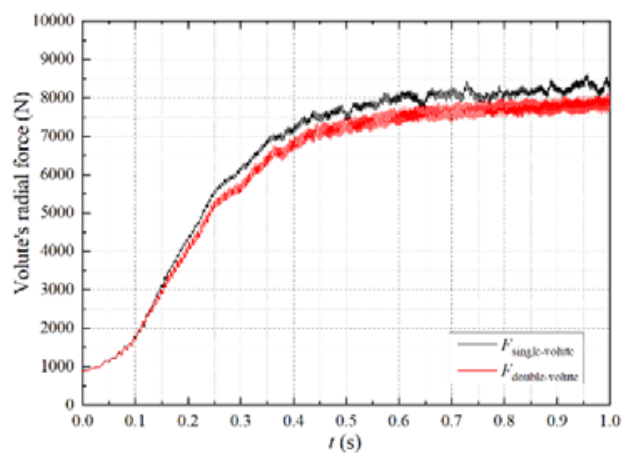

Fig. 11. Radial force curves of volutes during startup.

\subsection{Transient radial force vector of impeller}

The distribution of the transient radial force vectors of impellers at each period of the single-volute and the double-volute centrifugal pumps during the starting process are shown in Fig. 12 and Fig. 13, respectively. The transient radial force vector distribution of the impeller rotates clockwise during startup. It exhibits a pentagonal spiral geometry and extends outwards with a pronounced periodicity. The number of impeller blades determines the spiral geometry. This is because the radial force of the impeller is influenced by the rotor-stator interaction between the impeller and the volute. When the blade passes through the tongue, the rotor-stator interaction is enhanced, making the radial force generated on the impeller correspondingly enhanced. As the number of impeller blades is five, the distribution of the transient radial forces in the coordinate system is a pentagram when the impeller has rotated for one period.

As shown in Fig. 12(a) and Fig. 13(a), the vector distribution of the impeller radial force in the coordinate system is in the clockwise direction within $0-0.1 \mathrm{~s}$. But the impeller rotates in the $\mathrm{x}$ direction as the axis of rotation and counterclockwise in the coordinate system. It can be concluded that the change direction of the transient radial force is opposite to the direction of the impeller's rotation. In the initial $0.4 \mathrm{~s}$ of the startup, the rate of change in rotational speed is large, and the transient radial force vector distribution of the impeller varies considerably. The pentagonal geometry composed of vector points is constantly diffusing outward. In the middle and later of starting, the transient radial force of the impeller gradually tends to be stable, and the transient radial force vector distribution appears to overlap in each period. As can be found from Fig. 13, the radial force vector distribution of the impeller in the double-volute centrifugal pump within $0.2 \mathrm{~s}$ is similar to the single-volute, which rotates clockwise and extends helically outward, and at the same time, has a certain symmetry. Within $0.2 \mathrm{~s}$ to $0.4 \mathrm{~s}$, the double-volute geometry plays a role in balancing the radial force of the impeller, and the five-pointed star spiral geometry formed by the radial force vector of the impeller begins to shrink toward the center of the circle, with the internal angle gradually becoming sharp and distorted. After $0.4 \mathrm{~s}$, the variation stabilizes, and the pentagram geometry composed of vector points is almost completely distorted and deformed. This phenomenon is mainly caused by the splitter geometry which intensifies the asymmetry of the shape of the volute. The difference in flow velocity between both sides of the double-volute splitter is small at the initial stage. The influence of asymmetric geometry on the transient radial force of the impeller is relatively weak. With the continuous improvement of rotational speed, the flow velocity difference between the flow channels on both sides of the splitter also increases. The effect of the asymmetrical geometry on the transient radial forces of the impeller is becoming increasingly apparent, which makes the distribution of the individual period vectors more complex and chaotic, with no apparent symmetry. After $1.0 \mathrm{~s}$, the impeller reaches the rated speed, and the radial force vector distribution of the impeller of the two volute geometry pumps has reached stability. There is no distinct change in each period.

\section{CONCLUSION}

In this paper, the influence of the volute geometry on the radial force of the centrifugal pump during starting is studied by numerical simulation. The volute of a centrifugal pump with a specific speed of 92.8 is redesigned, and two kinds of volute geometry centrifugal pumps meeting the same external 


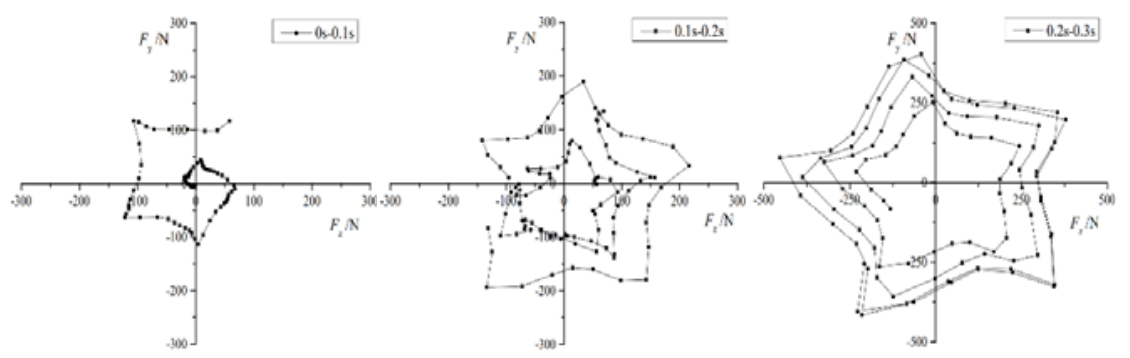

a) 0-0.1s

b) $0.1 \mathrm{~s}-0.2 \mathrm{~s}$

c) $0.2 \mathrm{~s}-0.3 \mathrm{~s}$

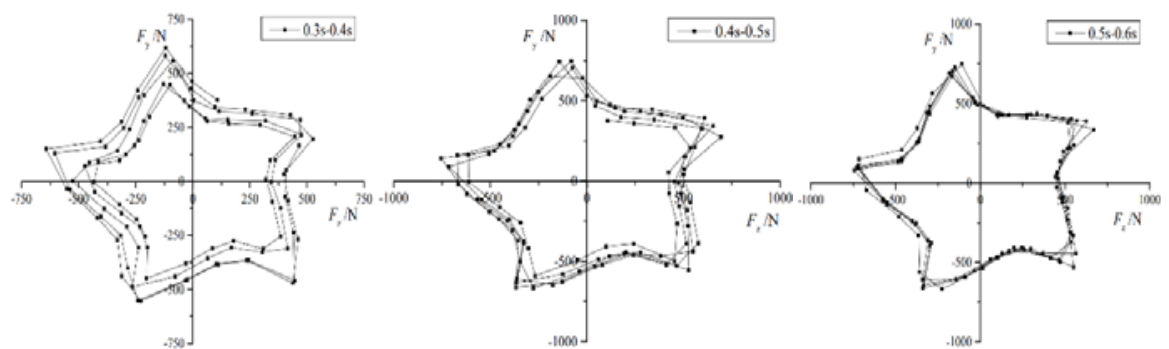

d) $0.3 \mathrm{~s}-0.4 \mathrm{~s}$

e) $0.4 \mathrm{~s}-0.5 \mathrm{~s}$

f) $0.5 \mathrm{~s}-0.6 \mathrm{~s}$

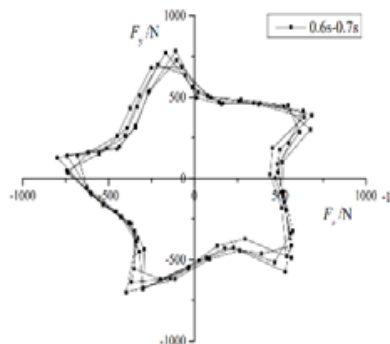

g) $0.6 \mathrm{~s}-0.7 \mathrm{~s}$

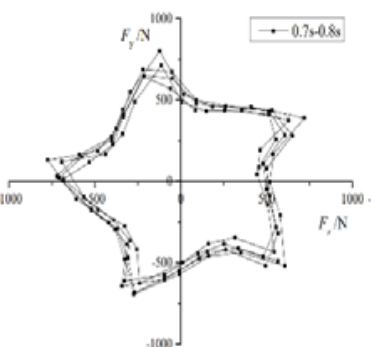

h) $0.7 \mathrm{~s}-0.8 \mathrm{~s}$

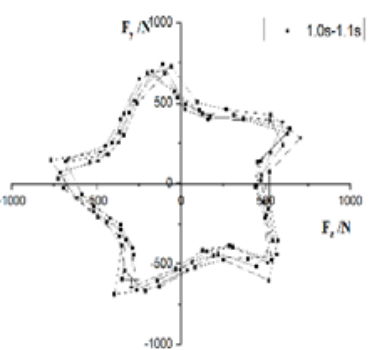

i) $1.0 \mathrm{~s}-1.1 \mathrm{~s}$

Fig. 12. Transient radial force vector distribution of single-volute impeller during startup.

characteristics are obtained. A circulation pipeline system is established to simulate the continuous transient process of the centrifugal pump starting accurately. The variations of radial force of singlevolute and double-volute centrifugal pumps during starting are compared and analyzed. The conclusions are as follows:

(1) Affected by the rotor-stator interference between the impeller and the volute, the radial force on the centrifugal pump has distinct pulsation. The amplitude of pulsation increases with rotating speed up during starting. The volute's transient radial force increases exponentially and is strongly impacted by rotating speed and flow rate.

(2) The transient radial force vector distribution of the impeller varies spirally and periodically during the start-up process. The spiral geometry is influenced by the number of blades, and the spiral direction is opposite to the rotation direction of the impeller. Because the splitter exacerbates the asymmetry of the volute geometry, the distribution of the transient radial force vector of the impeller of the double-volute centrifugal pump is more complicated and chaotic than that of the singlevolute and lacks symmetry. However, the doublevolute geometry can better improve the internal flow state of the centrifugal pump during the startup process.

(3) The double-volute geometry can effectively reduce the radial force and pulsation amplitude on the impeller during the starting process of the centrifugal pump, reducing about $80 \%$ at rated speed. It can also reduce the radial force on the volute to a certain extent $(-3 \%$ at rated speed), which is helpful to reduce the generation of vibration and noise, and improve the service life of the pump. Therefore, it is recommended to use the double-volute as the pumping chamber in some special fields where pump rapid start-up technique is required.

\section{DECLARATION OF CONFLICTIN INTERESTS}

The author(s) declared no potential conflicts of interest with respect to the research, authorship, and/or publication of this article. 


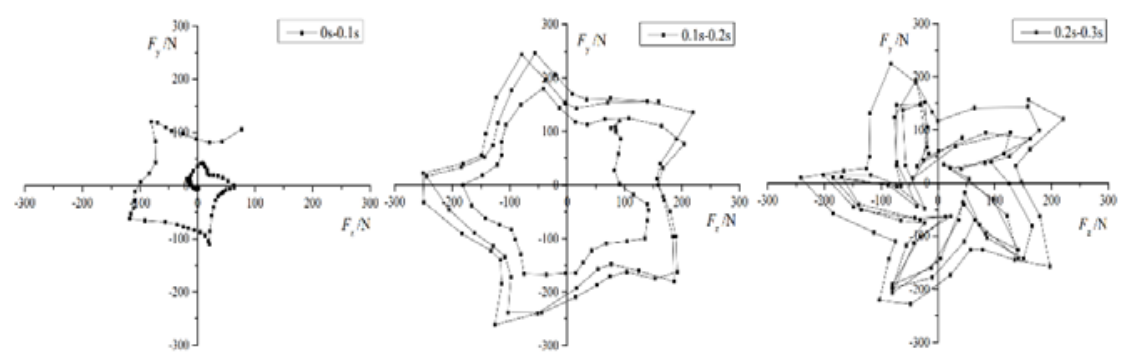

a) $0-0.1 \mathrm{~s}$

b) $0.1 \mathrm{~s}-0.2 \mathrm{~s}$

c) $0.2 \mathrm{~s}-0.3 \mathrm{~s}$

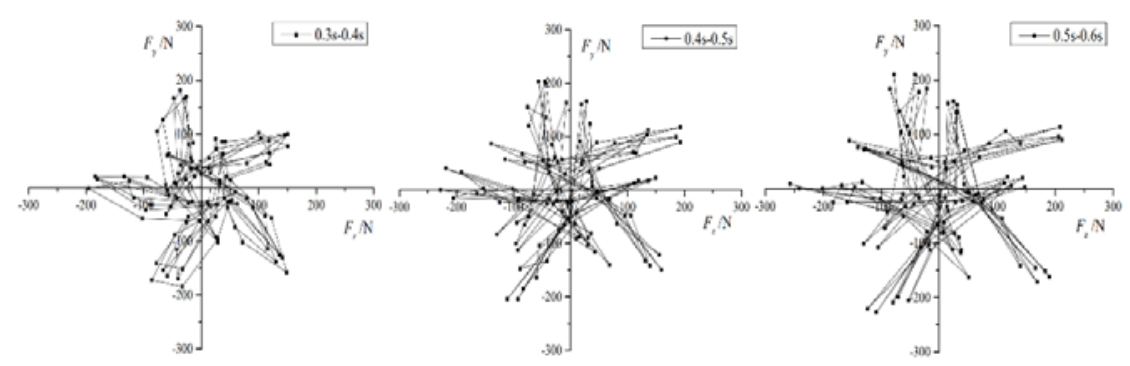

d) $0.3 \mathrm{~s}-0.4 \mathrm{~s}$

e) $0.4 \mathrm{~s}-0.5 \mathrm{~s}$

f) $0.5 \mathrm{~s}-0.6 \mathrm{~s}$

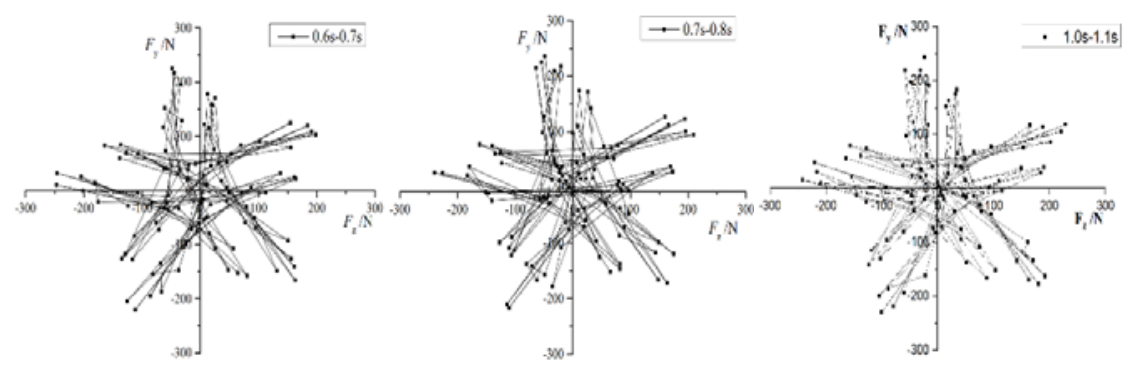

g) $0.6 \mathrm{~s}-0.7 \mathrm{~s}$

h) $0.7 \mathrm{~s}-0.8 \mathrm{~s}$

i) $1.0 \mathrm{~s}-1.1 \mathrm{~s}$

Fig. 13. Transient radial force vector distribution of double-volute impeller during startup.

\section{ACKNOWLEDGEMENTS}

The authors would like to thank the financial support from National Key Research and Development Program of China (Grant no. 2016YFB0200901 and Grant no. 2017YFC0804107), National Natural Science Foundation of China (Grant no. 51579117 and Grant no. 51779106).

\section{REFERENCES}

Barrio, R., E. Blanco, J. Parrondo, J. González and J. Fernández (2008). The effect of impeller cutback on the fluid-dynamic pulsations and load at the blade-passing frequency in a centrifugal pump. Transactions of the ASME Journal of Fluids Engineering 130(11), 111102.

Chalghoum, I., S. Elaoud, H. Kanfoudi and M. Akrout (2018). The effects of the rotor-stator interaction on unsteady pressure pulsation and radial force in a centrifugal pump. Journal of Hydrodynamics 30(4), 672-681.
Cui, B., X. Li, K. Rao, X. Jia and X. Nie (2018). Analysis of unsteady radial forces of multistage centrifugal pump with double volute. Engineering Computations 35(3), 1500-1511.

Duplaa, S., O. Coutier-Delgosha, A. Dazin, O. Roussette, G. Bois and G. Caignaert (2010). Experimental study of a cavitating centrifugal pump during fast startups. Journal of Fluids Engineering 132(2), article 021301, 1-12.

Fu, S., Y. Zheng, K. Kan, H. Chen, X. Chen, X. Han and X. Liang (2020, February). Numerical simulation and experimental study of transient characteristics in an axial flow pump during start-up. Renewable Energy 146, 1879-1887.

Hao, Y. and L. Tan (2018, November). Symmetrical and unsymmetrical tip clearances on cavitation performance and radial force of a mixed flow pump as turbine at pump mode. Renewable Energy 127, 368376.

Hu, F., X. D. Ma, D. Wu and L. Q. Wang (2012). 
Transient internal characteristic study of a centrifugal pump during startup process. IOP Conference Series Earth and Environmental Science, Beijing, China.

Li, W., L. Ji, W. Shi, L. Zhou, X. Jiang and Y. Zhang (2018). Fluid-structure interaction study of a mixed-flow pump impeller during startup. International journal for computeraided engineering and software 35(1), 18-34.

Pei, J., W. J. Wang and S. Q. Yuan (2014). Statistical analysis of pressure fluctuations during unsteady flow for low-specific-speed centrifugal pumps. Journal of Central South University 21(003), 1017-1024.

Shi, W., L. Li, R. Xu, B. Wang, L. Tan and L. Zhou (2020). Effect of blade slotting on radial force of single vane centrifugal pump. Journal of Drainage and Irrigation Machinery Engineering 38(9), 865-870,890.

Shim, H. S., A. Afzal, K. Y. Kim and H. S. Jeong (2016). Three-objective optimization of a centrifugal pump with double volute to minimize radial thrust at off-design conditions. Proceedings of the Institution of Mechanical Engineers Part A Journal of Power \& Energy 230(6), 598-615.

Tan, M., Y. Lian, X. Wu, R. Ding and K. Chen (2017). Unsteady dynamics in double channel pumps. Journal of Drainage and Irrigation Machinery Engineering 35(12), 1024-1029.

Thanapandi, P. and R. Prasad (1994). A quasisteady performance prediction model for dynamic characteristics of a volute pump. Proceedings of the Institution of Mechanical Engineers Part A Journal of Power \& Energy 208(1), 47-58.

Thanapandi, P. and R. Prasad (1995). Centrifugal pump transient characteristics and analysis using the method of characteristic. International Journal of Mechanical Sciences 37(1), 77-89.

Tsukamoto, H. and H. Ohashi (1982). Transient characteristics of a centrifugal pump during startup period. Journal of Fluids Engineering 104(1), 6-13.

Tsukamoto, H., S. Matsunaga, H. Yoneda and S. Hata (1986). Transient characteristics of a centrifugal pump during stopping period. Journal of Fluids Engineering 108(4), 392399.

Wu, D., P. Wu, Z. Li and L. Wang (2010). The transient flow in a centrifugal pump during the discharge valve rapid opening process. Nuclear Engineering \& Design 240(12), 4061-4068.

Yang, C. and B. Wang (2010). 3-D numerical simulation on transient characteristics of centrifugal pump during starting period. Journal of Drainage and Irrigation Machinery Engineering 28(2), 36-40.

Yusoff, M. D., M. H. Lim, M. R. Yahaya and J. Azman (2016). Exit Geometry Modifications of Double Volute Centrifugal Pump for Vane Passing Frequency Vibration Resolution: A Case Study. Advanced Engineering Forum, 82-90. 